\title{
Research on Integrated Management in Book, Information and Archives
}

\author{
Hui Wang \\ University Library, Jilin Agricultural University, 130118 Changchun, PR China \\ E-mail.13104452100@163.com
}

\begin{abstract}
Historically, books and archives have the same origin without any distinction. However, with the continuous development of society, the information requirements and demands are increasing. Therefore, books separate from archives, go farther and farther away in their respective directions, and thus form two separate systems. As a saying goes, this world will separate after long time united, and also will do the opposite after long time splitting. During the separation course for many years, history and reality require them to unite again, which are feasible under the demands of information integrity and is consistent with the essential requirements of unity between books and archives. In addition, the increasing popularity of information technology and network has made the integrated management in books and archives possible, which will also become strong supports and guarantees for their unity.
\end{abstract}

Keywords-Integrated Management; Books and Archives; Separation and Unity; Internet Age

\section{INTRODUCTION}

In the advent of information technology and networking eras, there is an increasingly urgent need for knowledge. As a carrier of knowledge, books and archives play an important role in the dissemination of knowledge. To facilitate management and better foster the dissemination and exchange of knowledge, it is a current development trend to carry out integrated management in books and archives. Therefore, this thesis introduces the integrated management in books and archives.

\section{THE DEFINITION OF INTEGRATED MANAGEMENT IN BOOKS AND ARCHIVES}

When conducting related researches on integrated management in books and archives, it is necessary to first give a definition of "integration". The so-called integration between books and archives is not to simply associate them but to facilitate the simultaneous introduction; certainly not to remove their coordinating relation and eliminate their essential difference. The integration between books and archives mainly unites two separate systems and thus creates a large entity. In the integration process, people will inevitably encounter many difficulties and problems, so it is essential to find their own strengths, eliminate the problems, achieve the sharing of resources, strengthen collaboration, and jointly provide users with better and convenient services under the background of network modernization.

While books and archives are substantially the same, simple unity cannot be realized, and the final reason is that they are essentially different. Firstly, books and archives differ in the source. Books can be obtained by purchase, and whether library collections are rich is linked to the specific investment funds. However, archives collections are different. It is only obtained by functional activities of various social institutions or government departments, which cannot be purchased. It is clearly defined in the law. Secondly, books and archives differ in the essential attribute, indicating the nature of the information they can provide is different. The original record is the essential attributes of archives, so the information recorded in archives is not processed, it is the most direct and most original first-hand information, and it is authoritative information reflecting the things or the original nature of things. However, books do not have this feature, because it differs from archives in their focuses, and it focuses more on whether the information is systematic and integral. As a result, the information recorded in books is artificially processed, indicating that it cannot become authoritative information just as archives but reference information. Thirdly, books and archives differ in service focus. As a first-hand material for description of things, the contents recorded in archives are directional, relatively simple and less rich than books. More importantly, when using archives, users must be subject to the confidential provisions and other provisions, having higher threshold. Nevertheless, the books are not the same. They not only have relatively complete contents, and the service objects are more massive. Besides, all book information could be read as long as relevant procedures are met, having lower threshold. Fourthly, books and archives differ in sources along with storage and safekeeping methods. Archives are produced under the background of social functional activities, the quantity is limited by the number of objects of social functional activities, and both of them retain a single copy. However, since books have extensive reading objects and they are not fixed groups, the stored books are also great in quantity, and their printing and publishing are adjusted and controlled by readers and markets. In short, although there are many differences between books and archives, as a very important carrier of social and cultural activities, both are the main information source of social activities. Despite many distinctions, they have a lot of similarities in management methods, future development and discipline attribute because of their historical origins, which are also the prerequisite for the integrated development of books and archives as well as the basis for common development and sharing of resources with the help of developed network technology. 


\section{REASONS FOR INTEGRATED MANAGEMENT IN BOOKS AND ARCHIVES}

Firstly, there are serious drawbacks between books and archives after their separation. After separation, books and archives go toward independent development, and gradually have their development strengths and distinctive features: Books focus on knowledge integrity and systematic property, whereas archives focus on authority and credentials value. Nevertheless, in the course of social development and progress, the obvious separation also becomes its shortcoming, resulting in failed exchange and communication of information. This is mainly shown in the following aspects: 1 . There is no business contact between books and archives works, so this is extremely unfavorable for making full use of various document information resources and rational distribution, resulting in a waste of resources and affecting the rational use and common development of resources. 2. The hard working without communication and relatively closed development system not only fails to satisfy the information needs of modern society, but also hinders the overall planning and demands of high-tech research results over books and archives. 3. As three major carriers of literature information system, their basic functions lie in carrying and transmitting information, and they have substantially the same working nature, purpose and procedures. Therefore, their independent development will be repeated, result in a lot of unnecessary wastes, and even bring adverse effects scientific development researches.

Secondly, integrated management in books and archives is also a requirement proposed by scientific integration along with the development of modern books and archives. With the continuous development of science and technology, modern science gradually becomes integrated. One of the biggest features of today's information age is the rapid growth of information amount. Under the background of information growth and acceleration of knowledge updating, archives and books as carriers of knowledge should be integrated, achieve the sharing of information resources through network technology, and thus better satisfy the social development demands on information resources. Libraries and archives have a more serious focus, so the partiality does not suit the information users' needs of integrated information resources. In today's increasingly high information society, an effective solution to the irrational layout of resources is to conduct integrated management, which is also favorable for the future development of archives and library. At present, the development of modern disciplines is characterized by high integrity level, and the mutual penetration and connection among disciplines gradually form a cross disciplinary type. Historically, books and archives have the same origin, and they witness the process of transforming from integrity to separation and from separation to integrity. Besides, under the current network information era, integration of books and archives has become a more and more evident trend, which is good news for the information exchange and integration of all disciplines.

Thirdly, integrated management in books and archives is also a requirement proposed by the development of knowledge economy and sharing of resources. Knowledge creating wealth is an eternal true proposition. Only by arming with knowledge and taking knowledge as a backup can an institution or local obtain rapid economic development. Common attributes for books and archives lie in that they are carriers of knowledge. The integrated management in books and archives can better achieve the systematic and integrated management in knowledge, realize the sharing of resources, significantly enhance the local or institutional knowledge reserve and the integrity level, and thus improve the chip of local or institutional wealth creation and the dynamic source of their economic growth. Compared with separate partial function, the integrated function is a result of one plus one being more than two. Therefore, the function of integrated management in books and archives is much stronger than the separate books or archives. The integrated management in books and archives makes their connections and collaborations become closer, promote the sharing and communication of resources, and thus form an integrated and comprehensive information system, so as to provide very comprehensive information resources to customers and create more values for the society.

\section{PROBlems AND SOLUtions OF INTEGRATED MANAGEMENT IN BOOKS AND ARCHIVES}

Firstly, the management system and policies have not been timely updated. This is because the current archives and books systems in China are independent of each other without any interference, and there is not much contact with each other and lack of communication and cooperation, causing great obstacles to the integration between books and archives. Besides, the fragmented system is characterized by irrational allocation of resources, more repetitive construction, large waste and other drawbacks. Also, there is no relatively uniform industrial standard or related laws and regulations to support the integrated management in books and archives. An important reason for the slow pace of integrated management in books and archives is that these policies have not been timely updated to provide effective protection. Furthermore, the leaders are not well aware about the importance and necessity of the integrated management in books and archives, which is also an important reason for the slow pace of integration construction.

The above problems can be solved by these methods. China should develop related policies, laws and regulations to realize reasonable allocation of information resources, consider establishing a national integrated management center of books and archives for the coordination of resources, stimulate the libraries and archives to actively participate in the integrated management, play a guiding and monitoring role, and protect the sharing of books and archives information resources. Additionally, China should actively start from the leadership level, create a strong "integrated" leadership, mobilize its positive attitude, and thus accelerate the system updating and obtain policy supports, and finally accelerate the integrated management in books and archives. 
Secondly, there is insufficient specific practice for integrated management in books and archives. Today, the integrated management in books and archives in China stays at the superficial and theoretical level without any practical research. The excessive theories and few practices are an armchair strategist. According to this phenomenon, China must seek experience from the Western developed countries, because the integration between books and archive in Europe and other Western countries develops very rapidly, particularly prominent in its business sector. From a business perspective, its internal books and archives are to satisfy its own needs, so that it will be more convenient to integrate the internal books and archives and other information resources. However, it is not integration in a simple form but an information network based on computer to provide information service for business development. For public books and archives, China may refer to the Library of Congress, manage books and archives by placing them into a separate department, and thus achieve integrated management.

Thirdly, there are not enough comprehensive talents. To realize the integrated management in books and archives, it is essential to own a professionals team with strong comprehensive strengths. In reality, however, China still lacks this kind of talents. This is because the current education system and archives and books causes are fragmented, and lack communications, which is a big blow to the integrated management in books and archives. Therefore, in order to solve this problem, China should train a number of related complex information management personnel as soon as possible. Fortunately, many domestic universities and educational institutions have studied books and archives as a subject, mainly aiming to train comprehensive talents in this regard. Besides, implement targeted training for the books and archives personnel, strive to make them actively learn knowledge and skills related to books and archives, and actively guide them to adapt to related operations of integrated management in books and archives.

Fourthly, currently China does not have any uniform industry norms and standards with this regard. Standardization of books and archives needs to be further coordinated and solved. There are access issues for information mixing of books and archives. According to this situation, China is required to actively accelerate the information indexing, classification and equipment standardization process of books and archives. When considering the features of books and archives, it is also necessary to consider the practicality and common property of integrated management, which is vital for the implementation process of resource sharing.

\section{CONCLUSIONS}

Although there are many similarities between books and archives, they also have distinct characteristics despite their differences. Therefore, when conducting the integrated management, it is necessary to consider the differences between them, respect and understand these differences, and seek common ground. Like when opening the archives information, it is essential to voluntarily abide by the relevant confidentiality of archives information, understand and respect the authority and credentials value of archives, and do not arbitrarily modify or paint archives contents. Based on seeking common ground and under the background of the Internet age, it is vital to own a relatively sound policy regime, normative industry standards and a relatively stable operating space and environment, and most importantly, reserve professionals with the overall quality. When meeting these factors, the integrated management in books and archives will be achieved soon.

\section{REFERENCES}

[1] Xinming Wang. Reflection on Integration of Archives and Books Information[J]. Inner Mongolia Science \& Technology and Economy. 2006(07)

[2] Xiaoyan Zhou. Initial Research on Integration of College Books Information[J]. Inner Mongolia Science \& Technology and Economy. 2012(14)

[3] Li Liu. Research on Theoretical Basis of Integrated Management in Archives, Books and Information[J]. Inner Mongolia Science \& Technology and Economy. 2013(05)

[4] Yi Li. Research on Management Model of Books, Information and Archives in New Era[J]. Journal of Zhengzhou Railway Vocational and Technical College. 2009(04)

[5] Binrong Liu. Research on Integration of Books, Information and Archives of Power Enterprises in the Information Era[J]. Technology and Market. 2011(04)

[6] Wenhang Xing. Information-based Development Path of Enterprise Books Information Archive $[\mathrm{J}]$. Science and Technology Innovation and Application. 2012(30)

[7] Ting Yu. Research on Integrated Construction of Books, Information and Archives in the Information Era[J]. China New Technologies and Products. 2012(16)

[8] Lihua Zhang. Integration of Books, Information and Archives Discipline Logic, Historical Process, Reality and Development Path[J]. Journal of Zhengzhou Railway Vocational and Technical College. 2009(03)

[9] Chunrong Yao. Books and Archives Management Should Better Serve the Engineering Design - Computer Management Process of Library and Archives in China Textile Industrial Engineering Institute[J]. China Investigation Design. 2003(07)

[10] Tongmei Zhang. Enlightenment of "7" Multiplier Effect on Books and Archives Services - Concurrent Research on Brand Strategy Service[J]. Lantai World. 2007(24) 